\section{John Rawls: a economia moral da justiça}

Hermano Roberto Thiry-Cherques ${ }^{1}$

Resumo: Neste texto, descrevo como o filósofo norte-americano John Rawls reformulou o pensamento moral contemporâneo, ao propor a subordinação da ética à justiça. Resumo a defesa que apresentou para uma moral fundada em um pacto que compensasse, sem tentar anulá-las, as assimetrias econômico-sociais do mundo em que vivemos. Concluo com uma discussão sobre as dificuldades teóricas que encontrou para absorver o pluralismo cultural, filosófico, político e religioso do Ocidente.

Palavras-chave: Ética, Justiça, Rawls, Contratualismo, Administração.

N o segundo termo do século XX, o pensador norte-americano John Rawls (1921-2002) provocou uma guinada nos estudos sobre a ética. Ao publicar, em 1971, Uma teoria da justiça, ofereceu a possibilidade teórica de integrar o sentimento moral com as liberdades públicas e individuais caras ao Ocidente.

Típico scholar norte-americano, Rawls foi professor na Universidade de Cornell e, depois em Harvard. Publicou Uma teoria da justiça, aos 50 anos de idade; o livro denso e austero se tornou um dos pólos inevitáveis de discussão ética. As polêmicas que se seguiram à sua publicação fizeram com que, nas décadas seguintes, Rawls revisse alguns dos pontos de sua abordagem, inserindo a questão da esfera pública (Political liberalism, 1993) e internacionalizando a sua perspectiva (The law of peoples, 1999).

Rawls construiu uma versão modernizada do Contrato Social. Mas o êxito extraordinário que teve o modelo que desenvolveu deve ser creditado, principalmente, à demonstração das fragilidades do pensamento igualitarista, que identifica a justiça com a igualdade econômica, e das distorções do liberalismo econômico, cego às injustiças decorrentes do mercado deixado à solta.

Rawls logrou teorizar com propriedade e perspicácia. Professou um construtivismo, que não pressupõe a existência de verdades morais objetivas; evitou o ranço do academicismo europeu; baseou-se, unicamente, na ideia de que, acordados princípios fundamentais, deles é possível derivar logicamente o ordenamento ético.

Na sua trajetória em busca do fundamento do que é justo, Rawls retomou a
Recebido:

02/03/10

Aprovado: 19/05/11

1. Professor Titular da Fundação Getúlio Vargas. E-mail:

Hermano.Roberto@fgv.br 
tarefa primária da ética, construiu uma explicação racional para o moralmente válido e procurou compreender a lógica que define a moralidade, não no sentido de "descobrir" como a moralidade se dá, mas no sentido de como construir uma ética objetiva.

Para determinar quais princípios morais deveriam reger a conduta humana, ele estudou concepções substantivas dos diferentes ordenamentos do justo (right), do bom (good), do valor moral e a sua relação com a consciência moral. Concluiu que a vida cotidiana não está submetida a um código de regras, mas a princípios. Para chegar a esses princípios, formulou uma concepção precisa da justiça, procurando demonstrar que o justo é anterior a qualquer outra consideração moral.

\section{O justo e o bom}

Desde Aristóteles, a justiça tem sido entendida como ordem universal, seja mediante a comutação (as ações e reciprocidade e de equilíbrio equitativo), seja mediante a redistribuição (as ações de proporcionalidade e do estabelecimento de méritos).

No sentido objetivo, sociopolítico, a ordem universal idealizada do que é justo é critério superior do princípio normativo da ação individual, da ação dos grupos e da ação das instituições, é um direito conforme uma norma, seja esta natural, divina ou positiva. No sentido prático, o justo é o ideal equitativo dos direitos e dos deveres, da precisão e do rigor, da justeza das ações. No sentido subjetivo, o justo é uma atividade moral, é o proceder que não está baseado em uma inclinação (amor, amizade, benevolência, simpatia), nem em uma obrigação para com o outro (virtude). É a medida de justificação das regras de convivência. Uma norma ideal que aspira estabelecer ou restabelecer uma ética. Resulta da crítica moral, que não se guia por nenhum rancor, por nenhum favor, mas por princípios formais. É sobre essa última concepção, da justiça como fundamento das regras de convivência, como norma fundada em princípios racionais, que Rawls erige o seu edifício teórico.

A justiça é uma invenção social que encerra um conceito, mas que admite muitas interpretações de como esse conceito se aplica na prática. Por isso, carece de uma teoria, de um processo lógico que estabeleça o conteúdo e a ordenação dos seus princípios normativos.

Rawls integra três noções ao princípio de justiça: o reconhecimento dos outros enquanto pessoas reais, com sentimentos e interesses; uma formulação kantiana, da ideia de não se tratar os outros como meios, mas unicamente como fins; 
a ideia de que o justo é anterior ao bem, querendo isto significar que o bem integra o justo.

O autor parte de uma análise deontológica, de como deveria ser uma sociedade bem ordenada justa, fundada em princípios. Teoriza o justo, determinando como seria a construção lógica de um contrato sobre os princípios equitativos, a partir de uma "posição original", uma situação análoga a um "estado da natureza".

\section{Construtivismo pluralista}

Esse "contrato ideal" seria a expressão de um acordo sobre os princípios fundamentais da justiça, estabelecido em um ato coletivo, por agentes livres, racionais e iguais, que abstraem sua posição socioeconômica particular. Pessoas, que, ignorando o que o futuro possa lhes reservar e desejosas de favorecer os seus próprios interesses, chegariam a um pacto fundado em preceitos necessariamente justos.

Nessa formulação, Rawls reuniu uma série de conceitos de várias origens. A ideia de estado da natureza da situação imaginária, do ser humano vivendo em estado puro, pré-social, bem como o conceito do pacto ou do contrato (de que, para escapar à barbárie, a humanidade teve que estabelecer um acordo políticosocial) são contratualistas. A noção do "véu de ignorância", dos agentes que abstraem tudo que não seja o conhecimento imediatamente disponível, inclusive as condições econômicas, políticas e sociais e as antevisões sobre o futuro, é retirada do idealismo (PL VIII § 4; 305). A concepção de que agentes racionais decidem de acordo com os seus interesses se inspira francamente no utilitarismo.

Rawls pode sintetizar esses conceitos em um todo porque o sistema que elaborou não se baseia em um critério, mas em um procedimento. Ele concebeu a tarefa da ética não como sendo a de descobrir princípios, mas a da estabelecer princípios mediante processos que permitissem alcançar um equilíbrio moral razoável.

A tese é a de que, sendo o procedimento racional e equitativo, o resultado desse procedimento também o será. A sua teoria não procura resolver a integralidade do problema da justiça absoluta, mas a dos princípios que regem a repartição moralmente justificável das vantagens sociais.

\section{O acordo}


A teoria da justiça é pluralista, isto é, compreende o universo social como composto de uma série de elementos heterogêneos. Mas sustenta a possibilidade de um ordenamento serial de princípios, de forma que um primeiro e mais importante princípio deve ser satisfeito antes de qualquer outro; Rawls situa, como anterior a todos os princípios, o da liberdade. Em seguida, vem o do reequilíbrio das desigualdades e desses dois princípios fundantes derivaria toda a justiça e, dela, toda a moral. A teoria propõe uma explicação hipotética, em que uma assembleia de pessoas livres se reúne para escolher os princípios que devem presidir a estrutura da sociedade (PL VII § 7; 275 e ss.)

As condições para o acordo são as seguintes: (TJ § 20 e ss.; 107 e ss.) i) as circunstâncias de escassez moderada da economia e de desinteresse mútuo entre os agentes; ii) o respeito às restrições formais do conceito de justo, isto é, generalidade, universalidade, publicidade, ordenação e determinabilidade; iii) a razoabilidade dos agentes; iv) o "véu de ignorância", ou seja, a abstração da situação particular e da situação social, econômica, psicológica e física do indivíduo.

A ideia é a de que, se alguém tem que escolher princípios, mas nada sabe sobre a sua posição e sobre o seu futuro, não podendo determinar quais princípios constitutivos da justiça poderiam ser vantajosos e quais poderiam ser desvantajosos para ele, tenderá a escolher princípios "neutros", de interesse geral, princípios que sejam bons para qualquer um e para todos. Sob essas condições, o acordo inicial determinaria, necessariamente, dois princípios (TJ § 60-68; 245 e ss.):

a) o da liberdade: cada pessoa deve ter direito igual ao mais amplo sistema de liberdades básicas. A justiça é dada, antes de tudo, pela liberdade de opinião e de consciência, igual para todos e que impera acima dos interesses econômicos, das aspirações político-sociais e das conviç̧ões religiosas. A liberdade deve ser a mais ampla, compatível com as liberdades alheias. Esse princípio é prioritário em relação a todos os outros;

b) o da diferença: segundo o qual as desigualdades socioeconômicas só podem ser consideradas justas se produzirem uma compensação, um reequilíbrio das situações, em especial para os membros menos favorecidos da sociedade. De modo que as desigualdades, para serem justas, obedecem a duas condições: propiciar o maior benefício aos menos favorecidos e garantir o acesso a cargos e posições em condições equitativas, isto é, em que as oportunidades e vantagens sejam acessíveis a todos, igualando a atribuição de direitos e de deveres. 
Os dois princípios de Rawls são, na verdade, três. O sistema é constituído por uma condição maior, a da liberdade, e de dois grandes princípios: o da diferença e o da igualdade. Formulada dessa maneira, a teoria da justiça se constitui como um "equilíbrio reflexivo", como resultado de uma ponderação lógica, pela qual a coerência da nossa perspectiva moral é obtida mediante o ajuste mútuo entre os juízos particulares, os princípios gerais e as construções teóricas. O equilíbrio reflexivo ou reflectivo se dá entre as concepções adotadas e as consequências que elas implicam, impõe um ajustamento dos princípios às convicções morais de uma cultura e admite a possibilidade de correções e ajustamentos.

Ignorando a posição que ocupará no sistema, cada um é racionalmente animado por seus próprios interesses. Cada agente considera a possibilidade pior, ou seja, que ocupará a posição social mais ínfima. A sua estratégia seria, necessariamente, a da minimização das perdas máximas e da maximização das perdas mínimas (maxmin), que consiste em assegurar-se que o pior resultado será o melhor possível. Os agentes tratariam, então, de buscar um equilíbrio das possibilidades e a determinação de juízos ponderados por meio de um conjunto de procedimentos.

\section{A liberdade e diferença}

O primeiro princípio, o da liberdade, corresponde à concepção de autonomia racional de Kant, mas dela difere, na medida em que é constitutiva do ser humano e não construída por ele. É um espaço de significação da vida e uma condição de dar sentido a ela, um fim (destinação) escolhido pela razão. Implica na razoabilidade (a capacidade de ter senso de justiça) que antecede, informa e limita o justo, que, por sua vez, indica a ética fundada na racionalidade (a capacidade de conceber o bem). O princípio inclui o conceito, de Locke, da liberdade dos meios necessários à preservação da vida, do corpo e das demais propriedades; e o de Rousseau, da vontade geral e da autonomia da conduta e da expressão.

Tais liberdades não são absolutas: são restritas e regulamentadas, mas sempre em nome de outras liberdades mais fundamentais. De outra forma, poderia ser o caso, por exemplo, de a liberdade de informação tolher ou prejudicar outra liberdade mais fundamental, como a da proteção contra julgamentos arbitrários (TJ § 31 e ss.; 159 e ss.; PL VIII § 9; 332 e ss.)

Mas a chave da teoria de Rawls repousa sobre o principio da diferença. De acordo com este princípio, todos os valores sociais - liberdades, oportunidades, renda e as bases sociais da autoestima (self-esteem) - devem ser distribuídos igualitariamente, desde que uma distribuição desigual não seja vantajosa para todos. Em outros termos: as distribuições desiguais só são aceitas se trazem vantagens 
para todos, caso contrário constituem-se em injustiças.

Selecionar o maximin significa escolher dentre as disposições possíveis a que torna mais elevadas as vantagens pessoais, bases do autorrespeito (self-respect), políticas (posições e prerrogativas) que podem ser esperadas por aqueles em posições mais fracas; "Mais do que isso: as desigualdades imerecidas devem ser compensadas de forma a compensar os déficits de justiça da igualdade liberal". Essa é uma noção complexa, baseada na regra utilitarista, mas dela diferindo ao se distanciar do equilíbrio direto do "ótimo de Pareto", (quando não é possível melhorar a posição de um indivíduo sem, ao mesmo tempo, piorar a situação de outro).

É um modelo seletivo, não igualitário ou isonômico, é uma função de esperança, não de caridade. As desigualdades de remuneração, por exemplo, são justas desde que reflitam o rendimento efetivo do trabalhador e/ou uma maior responsabilidade, desde que essa desigualdade contribua para estimular o progresso e as esperanças de todos (PL VII § 5; 270-271).

Rawls se propõe estabelecer os meios necessários ou "bens", de modo que tal justiça possa se efetivar. Para além da disposição de bens naturais, como a capacidade intelectual e os talentos, que estão fora do nosso controle pessoal e institucional, ele propõe a ordenação consertada dos "bens sociais", constituídos tanto de bens morais (abstratos) como de bens materiais, decorrentes de (PL II § 7; 82) um princípio igualitário ("igualdade democrática") de distribuição para os bens básicos imateriais - correspondente ao direito igual às liberdades fundamentais iguais, que sejam compativeis com as liberdades para todos -, em que a simetria é exigida. O princípio igualitário inclui: i) as modernas liberdades individuais, isto é, os direitos de autonomia privada (consciência, pensamento, religião, opinião, movimento, ocupação, respeito próprio e autodesenvolvimento); ii) as tradicionais liberdades políticas, isto é, os direitos de autonomia pública (expressão, voto e elegibilidade, participação, reunião, o direito à propriedade, à integridade física, à proteção contra julgamentos e detenções arbitrárias, à segurança).

A igualdade de oportunidades deve ser assegurada pelas instituições educacionais, políticas, etc., por ser vantajoso que todos possam concorrer em igualdade de condições em um principio não igualitário de distribuição de bens básicos materiais, sociais, econômicos, poder (posição e cargo), em que a assimetria é justificada pelo que é razoável esperar que sirva de benefício para todos, de modo que as oportunidades estejam abertas a todos. A liberdade precede a todos os outros princípios porque a suspensão das liberdades e direitos não pode ser compensada por maiores vantagens sociais e econômicas, sob pena de viciar todo o sistema, torná-lo instável. 
A distribuição, ao favorecer os mais pobres e os socialmente inferiorizados só será justa ao contribuir para melhoria desses mesmos agentes. Equação que corresponde a um equilíbrio assimétrico das vantagens e prerrogativas, na medida em que a distribuição em favor dos mais ricos e socialmente privilegiados também será justa se tiver o mesmo efeito de trazer "vantagens para todos". Por exemplo, o empreendedor não recompensado não investirá. Como é do interesse de todos que alguém receba mais por ter mais iniciativa, o lucro obtido por quem se arrisca a empreender é justo e moralmente correto. Isso desde que o aumento das expectativas de ganhos dos empresários venha a deixar a classe operária em melhor situação.

\section{Contratualismo}

Rawls fez as tradições deontológica de Kant e teleológica de Mill convergirem para a esfera da tradição do contrato. Ele se baseou em ideias aristotélicas (mitigação das desigualdades), utilitaristas (consequências dos atos morais) e kantianas (razão prática). Mas a pedra de toque da teoria da justiça é a retomada da filosofia do contrato social: a ideia de um acordo racional ou razoável, baseado no interesse particular e universal e fruto do consentimento de todos.

No contrato, a sociedade, a quem ninguém tem a obrigação de aderir, é definida como um sistema equitativo e voluntário de cooperação entre indivíduos. A teoria da justiça descarta o critério natural e o critério da eficácia como fundamentos de ordenamento moral da sociedade. Opõe-se às doutrinas que imperaram na segunda metade do século XX. As ideologias do igualitarismo e o do liberalismo absoluto e as doutrinas morais do intuicionismo, do emotivismo, do subjetivismo e do utilitarismo. Ainda, contrapõe-se às posições igualitaristas e liberais do bem estar de todos porque, na perspectiva de Rawls, para que o bem prevaleça, o correto e o justo devem ser anteriores ao bom. Contrapõese, também, ao intuicionismo, ao emotivismo e ao subjetivismo porque essas doutrinas supõem o pluralismo de princípios, não o pluralismo de ideias, a aceitação das diferenças interculturais e intersubjetivas. Opõe-se ao utilitarismo, porque o critério de decisão de Ralws é teórico, genérico e permanente, não um critério de decisão prático, particular e imediato. Ele critica, especialmente nos utilitaristas, o princípio segundo o qual uma sociedade é justa quando suas organizações são instituídas de forma a alcançar a maior soma de satisfação para o conjunto de indivíduos. Para Rawls, o princípio da utilidade é incompatível com a ideia de reciprocidade: é injusto porque submete os direitos individuais ao cálculo do interesse social. Rawls não aceita a tese utilitarista do balanço automático das perdas e ganhos, transpondo-a de uma moral empírica fundada em fatos, para uma moral a priori, fundada em princípios. 
Uma teoria que propõe a supressão das diferenças resultantes da "loteria natural" (talentos) e da "loteria social" (destino) ,porque são "moralmente arbitrárias" e, portanto, são moralmente arbitrários os estados resultantes dos seus efeitos. A "arbitrariedade moral", no sentido que lhe dá Rawls, é aquela resultante da natureza e do acaso, diferente, portanto, da arbitrariedade causada por uma decisão não justificada racionalmente (preconceitos, maldades, jugo, etc.). Ele confere ao Estado responsabilidades no fornecimento de bens públicos e no controle das instituições responsáveis pelas liberdades individuais e coletivas e pela distribuição equitativa desses bens. Prega também a redistribuição compensatória: os que recebem maiores vantagens têm o dever de compensar a parcela maior recebida em decorrência do que a sociedade lhe proporcionou (por exemplo, impostos progressivos) (TJ § 81; 406).

\section{A pessoa}

O utilitarismo, o igualitarismo e as demais posições contemporâneas são marcadas pela eficácia e pela abstração. As pessoas são consideradas como tendo necessidades e preferências idênticas. Não se leva em conta as relações intersubjetivas e o bem comum como empresa diversa da soma dos interesses particulares, bem como a reciprocidade implícita no conceito de justiça, uma vez que se julga correto que os indivíduos sacrifiquem seus interesses sem receberem nada em troca.

Contratualista, Rawls concebe a pessoa como sujeito de direitos. Toma cada um não a unidade individual, mas como a pessoa capaz de imaginar, de distinguir, de se expressar e de reivindicar. A pluralidade das pessoas é essencial ao seu modelo. O autor considera como bens primários as liberdades de pensamento e de consciência, de movimento e as prerrogativas de autorrespeito, de escolha de ocupação e de acesso a posições e a riquezas, enfim os bens necessários à sobrevivência digna de todo qualquer individuo (TJ § 33; 166). Ele considera, como bens básicos, os valores fundamentais: a legitimidade, o respeito, a segurança, a liberdade, a educação, as oportunidades profissionais, a renda, as subvenções, bases sociais da autoestima, do reconhecimento de nosso próprio valor (TJ § 67; 325).

O princípio da igualdade equitativa de oportunidades não pressupõe que todos somos iguais, independentemente da nossa condição natural - saúde, dotes, etc. - e da nossa condição social. Ao contrário, esse princípio reclama apenas que pessoas que possuam as mesmas condições naturais tenham possibilidade de acesso às posições e às condições de progresso. O sujeito moral, sendo uma pessoa livre, igual aos demais, razoável e dotada de senso de justiça, 
empresta lógica e coerência às instituições burguesas como a família, a constituição política democrática, a propriedade, a economia de mercado. Não se trata, por exemplo, de garantir que pessoas sem talento e capacidade ingressem nas universidades, mas de garantir que pessoas com os mesmos talentos e capacidades possam ter condições de acesso à educação superior. Como não se trata de o empregado ter o direito de participar das decisões da empresa, mas de ter a possibilidade de ascender às posições que detém essa prerrogativa.

\section{Críticas}

A teoria de Ralws foi recebida com duras críticas. Algumas se referem às implicações dos resultados a que chegou, mas a maioria se dirige aos pressupostos do sistema.

Censura-se, por exemplo: i) que não há base nos pressupostos da teoria que levem a concluir que é vantajoso amparar os que não podem suprir a si mesmos (desempregados, incapacitados para o trabalho, doentes físicos, psíquicos e mentais); ii) que, ao contrário do que supõe o principio da diferença, não há como garantir os efeitos e as proporções nem do aumento, nem da manutenção, nem da redução das assimetrias econômico-sociais; iii) que a arbitrariedade natural dos dotes e talentos não pode ser considerada moral, não havendo como fundamentar em termos éticos a compensação pela falta de aptidão (SEN, 1998). Mas as objeções mais contundentes vão contra a confusão entre a concepção deontológica do justo e a concepção teológica da justiça dada pelo autointeresse (NOZICK, 1991). Argumenta-se que o ponto de vista dos princípios morais, claros e precisos, e que o ponto de vista dos interesses particulares, variáveis e ponderados, são inconciliáveis com a primazia do princípio da liberdade (HABERMAS, 2004).

Argumenta-se, também, contra o véu da ignorância, que não é verdade que os seres humanos dão sempre e em qualquer circunstancia maior valor à liberdade do que às vantagens econômicas, que preferem a liberdade à condição de penúria e que não há como decidir na ausência total de referências. Outro argumento contra a proposição de Rawls é o de que, se alguém tem que escolher princípios, mas nada sabe sobre a sua posição e sobre o seu futuro, não podendo determinar quais princípios constitutivos da justiça poderiam ser vantajosos e quais poderiam ser desvantajosos para ele, não terá como escolher princípios "neutros", de interesse geral, princípios que fossem bons para qualquer um e para todos - a determinação isenta das escolhas. Critica-se, ainda, Rawls pela suposição de que existam seres humanos desraigados, isolados da uma situação étnica, social e política. Por último, argumenta-se contra a estratégia 
maximim, que é não natural, já que os seres humanos, ao contrário do que supõe o autor, tendem a arriscar-se em uma estratégia maxmax, e contra o próprio acordo. Por fim, argumenta-se que os seres humanos tendem a decidir com base em sentimentos (sympatheia) e não com base em uma lógica estrita, e que não há como demonstrar que todos os indivíduos consentiriam com os princípios da liberdade e da diferença (SEN, 1998 e SANDEL, 1998).

\section{Aperfeiçoamento e síntese}

Face às críticas sobre a concepção monológica de racionalidade implicada no seu construtivismo, Rawls reformulou alguns pontos da teoria da justiça em favor de uma noção dialógica de uma racionalidade prática. Mas manteve constantes os procedimentos e os princípios de justiça, limitando apenas o alcance da concepção, circunscrevendo o consenso aos que aceitam as concepções liberais.

Nos trabalhos posteriores à Teoria da justiça, argumentou que a posição original, o véu de ignorância, seria removido por "interesses de ordem maior" que orientam os "poderes morais", a capacidade de formular, revisar e perseguir uma concepção racional do bem e a capacidade de entender, aplicar e agir de acordo com um senso de justiça.

Rawls desenvolveu seus argumentos, tornando-os mais compatíveis com o pluralismo e com uma concepção pública de justiça. Segundo essa nova concepção, os princípios livremente escolhidos pelos indivíduos devem ser endossados mediante o acordo das posições culturais, filosóficas e religiosas presentes na sociedade.

Nos seus últimos anos, Rawls escreveu ensaios desenvolvendo a teoria do justo e do moral. A maioria foi reunida na coletânea Political liberalism, de 1993. Nesses ensaios, ele aperfeiçoou e modificou suas concepções em função: i) do "fato do pluralismo", ou seja, da multiplicidade de crenças, filosofias, morais, impede o consenso, e ii) do entendimento que a unidade só seria possível dentro do quadro do pluralismo cultural, isto é, dos valores compartilhados. Formulou, então, uma concepção política de justiça, fundada nos pontos em comum das diversas crenças, doutrinas e modos de pensar de uma sociedade, evitando as posições de confronto. A ideia que desenvolveu foi a de se conseguir um consenso por interação (overlapping consensus), uma dimensão pública, não privada do razoável, uma noção compreensiva que incluísse concepções filosóficas, religiosas e culturais que pudessem ser aceitas universalmente, de forma livre, racional e equitativa. O "consenso sobreposto" impõe o respeito tolerante a todas as noções particulares de bens. Exige que as concepções sobre o justo se coadunem com os bens primários e com os princípios básicos e 
que sejam aceitos por cada uma das orientações morais existentes na sociedade (PL IV § 4; 150-54) da defesa do "equilíbrio reflexivo", pelo qual a coerência da nossa perspectiva moral é obtida mediante o ajuste mútuo entre os juízos particulares, os princípios gerais e as construções teóricas como contrato social (PL 1 $\S 4 ; 28)$. Nessa perspectiva, cada sujeito representativo esclarece a sua posição em relação à distribuição dos bens. A multiplicidade das posições é harmonizada em acordo com princípios que Rawls supõe universais, capazes de ordenar a cooperação e a vida coletiva. É um procedimento analítico, que contorna o problema da deontologia, dos princípios eternamente fixos por uma razão imutável e que se baseia em argumentos razoáveis. Com a nova ideia do equilíbrio reflexivo, os princípios igualitaristas deixam de ser universalizados. Há situações em que são rejeitados, como há situações em que são exigidos (BOUDON, 2000, p. 3) - de ter aceito não ser possível se partir de zero em uma situação original inteiramente neutra.

O ponto de partida seria dado, então, por determinados valores, que denomina de "pensamentos intuitivos fundamentais"; ao ter cingido o modelo às sociedades democráticas que prezam a liberdade, a igualdade e a equidade na produção e distribuição de bens materiais e morais (PL I § 6 pág. 35) e, principalmente, negado que a sua teoria seja uma nova filosofia moral, tomando a justiça equitativa exclusivamente como forma de ordenação do convívio em uma sociedade bem ordenada. O modelo se limita, então, a propor uma ética normativa, fundada na razoabilidade pluralista de todas as doutrinas morais que, apesar de se oporem, persistem através dos tempos e são compatíveis com os princípios básicos de liberdade e igualdade democrática.

Rawls deu atenção especial à questão da distribuição dos bens públicos, aqueles necessários à dignidade da vida coletiva. Os bens que não podem ser oferecidos a cada pessoa individualmente, como a educação, o controle de doenças, as águas e esgotos, a segurança, o transporte, a moradia. Os bens que constituem o exercício do controle econômico, como aferição de custos e preços, o intercâmbio e a transparência das informações sobre os interesses, a transferência ou redistribuição (por exemplo, renda mínima), a distribuição, mediante o fornecimento de bens coletivos. Enfim, os bens que, por natureza, são indivisíveis, como a segurança da nação contra uma ameaça externa. Insistiu que o Estado tem obrigação de garanti-los (TJ § 42; 201 e ss.).

A idealização do liberalismo político e do econômico é, para muitos críticos, o ponto mais fraco do modelo de Rawls. Ele jamais vai contra o liberalismo. Propõe apenas que o mercado aberto seja controlado. No seu modelo, a responsabilidade pelo fornecimento dos bens públicos deve ser governamental, mas o fornecimento em si pode ser tanto governamental como concedido à iniciativa privada. Já a decisão do que integra a lista dos bens públicos e a prioridade 
na oferta deve ser livremente escolhida pela população (TJ § 37; 181 e ss.). Sejam quais forem as críticas que se possa fazer à forma de pensar de Rawls, e ainda que nem todas as objeções tenham sido removidas, não há dúvida de que ele renovou a reflexão moral e que atingiu o objetivo de responder à questão do que poderia ser a justiça no mundo contemporâneo, mediante a conciliação dos ideais de igualdade e de liberdade nas sociedades pluralistas.

Ao propor uma deontologia, uma doutrina fundada em princípios, em que um ato é justo e moral não porque é "bom", mas porque é consoante o reto proceder, contribuiu enormemente para dar inicio à superação do embate improdutivo entre um igualitarismo impossível de ser alcançado e o reino iníquo do mercado, que marcou a segunda metade do século XX.

Abstract: In this article I describe how the North-American philosopher John Rawls has reformulated contemporary moral thinking in proposing subordination of ethics to justice. I synthesize his defense of a morality based on an agreement that compensates, without attempting to nullify, current socio-economic asymmetries. I conclude with a discussion of the theoretical difficulties he encountered in absorbing cultural, philosophical, political and religious Western pluralism in his theory.

Keywords: Ethics, Justice, Rawls, Contractarianism, Management.

\section{Referências Bibliográficas}

ARNSPERGER, Christian; VAN PARIJS, Philippe. Ética econômica e social. Tradução de Nadyr de Salles Penteado e Marcelo Perine; São Paulo: Edições Loyola, 2003.

BOUDON, Raymond M. "Plurarité culturelle et relativisme". Comprendre n. 1 : 311-339, 2000.

FELIPE, Sônia T. "Rawls: uma teoria ético-política da justiça" In: M. A. de Oliveira (org.), Correntes fundamentais da ética contemporânea. Petrópolis: Vozes, 2000.

HABERMAS; Jürgen. "Liberalismo político: uma discussão com John Rawls", In: Tradução de George Sperber, Paulo A. Soethe e Milton C Mota, A inclusão do outro. São Paulo: Loyola, 2004.

KERSLING, Wolfgang. "John Rawls: justiça distributiva e liberalismo político" In: J. Henningfeld, H. Janson (orgs.) Filósofos da atualidade; Tradução de Ilson Kayser, p. 191-214. São Leopoldo: Editora Unisinos, 2006. 
NOZICK, Robert. Anarquía, Estado y Utopía [1974]. México DF: Fondo de Cultura Economica, 1991.

OLIVEIRA, Nythamar de. Rawls. Rio de Janeiro: Jorge Zahar Editores, 2003.

RAWLS, John. Uma teoria da Justiça. Tradução de Vamireh Chacon. Brasília: Editora Universidade de Brasília, 1981.

Lua Nova, 1992.

"Justiça como equidade: uma concepção política, não metafísica". . Political liberalism. New York: Columbia University Press, 2000.

RUSS, Jacqueline. Pensamento ético contemporâneo. Tradução de Constança Marcondes César. São Paulo: Paulus, 1999.

SANDEL, Michel J. Liberalism and the limits of justice, Cambridge: Cambridge University Press, 1998.

SEN, Amartya. Inequality reexamined, Oxford: Oxford University Press, 1995 